Gut, 1985, 26, 175-178

\title{
Changing patterns of coeliac disease frequency: an analysis of coeliac society membership records
}

\author{
M J S LANGMAN, T H MCCONNELL, D J SPIEGELHALTER, \\ AND R B MCCONNELL \\ From the Gastroenterology Unit, Broadgreen Hospital, Liverpool, and University Department of \\ Therapeutics, City Hospital, Nottingham
}

SUMmaRY Examination of Coeliac Society records from eight areas of England has shown that the number of members rose with birth dates from 1900 to 1972, apart from a decline between 1941 to 1962, and then fell steeply. The steep decline in the number of members with birth dates after 1972 is unexplained, and is unlikely to be accounted for by change in diagnostic practice or registration and may reflect a true fall in disease incidence; but the fall in numbers of members with birth dates from 1941 to 1962 is explainable by a tendency for the disease to remit in adolescence or early adult life.

We know little about the epidemiology of coeliac disease except that gluten sensitivity tends to develop in particular families, that it tends to be associated with HLA status, and to occur after about one in every thousand births in the United Kingdom. ${ }^{12}$ It has lately been suggested that childhood coeliac disease has become less common, ${ }^{3-6}$ and that though children born in certain years may be particularly prone to develop the disease, those born in some other years may be very unlikely to develop it. Thus no child born in County Galway in 1964 had been found to have coeliac disease by 1979, while 17 of those born in 1972 had developed it. ${ }^{7}$

We have therefore examined the records of the Coeliac Society membership to determine if any particular frequency patterns were discernible which could be related to the patients' date of birth or to his or her age or date of diagnosis.

\section{Method}

One of us (THMcC) prepared lists setting out the ages at diagnosis, years of diagnosis and dates of birth of Coeliac Society members living in eight regions (Avon, Birmingham, Bristol, Derbyshire, Liverpool, Nottinghamshire, Merseyside, and West

\footnotetext{
Address for correspondence: Professor M J S Langman, Department of Therapeutics, Floor C, South Block, University Hospital, Nottingham NG7 2UH.

Received for publication 30 April 1984
}

Midlands) who joined the Society before July 1982. We have used these lists to construct tables of frequency distributions to determine if any significant fluctuations in patterns were detectable according to date of birth, or to age or date of diagnosis. The pattern of change according to age was then compared with a smooth trend to determine if any significant deviations were present. $^{8}$

\section{Results}

One thousand nine hundred and thirty two Society members from the eight areas were born between 1900 and 1981 and had their disease diagnosed between 1950 and 1981 . The numbers rose gradually for those with birth dates from 1900 to 1940 (Fig. 1), and the pattern was consistent with a linear change according to a weighted regression. None of the individual figures for this period were significantly high or low. The numbers of members with birth dates from 1941 to 1962 were lower than expected from the regression line, and this fall was highly significant $(\mathrm{p}<0.01)$. Numbers of diagnoses then rose for individuals born from 1963 to 1972 and then declined steeply.

The Table shows the dates of diagnoses of members according to their age. The proportion of early childhood diagnoses fell with time while the proportions of diagnoses made in adult life rose equivalently. Thus half of all diagnoses before 1968 


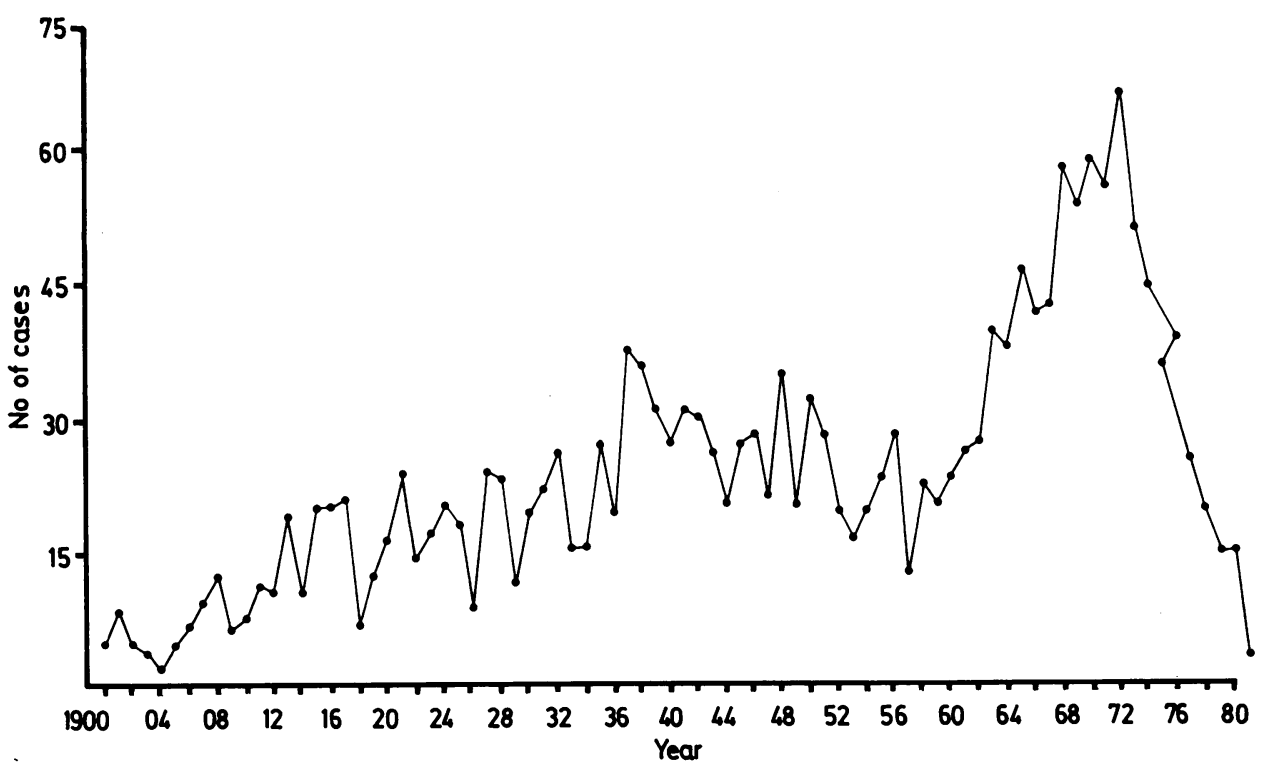

Fig. 1 Frequency distribution by date of birth of Coeliac Society members born between 1900 and 1981 and diagnosed between 1950 and 1981 .

were made in children under the age of five, and less than a third in adults aged 25 or more, while from 1978 onwards less than a sixth of diagnoses were made in early childhood and two-thirds were made in adult life. These changes occurred consistently, and were independent of the absolute number of diagnoses made in any particular period.

Figure 2 gives the cumulative numbers of diagnoses made in all individuals born between 1972 and 1980. It shows that curves of increase were

Table Numbers and percentage of Coeliac Society members according to age and to year of diagnosis

\begin{tabular}{|c|c|c|c|c|c|c|c|}
\hline \multirow[b]{2}{*}{ Year of diagnosis } & \multicolumn{7}{|c|}{ Age in years } \\
\hline & $0-4$ & $5-9$ & $10-24$ & $25-39$ & $40+$ & Not & \\
\hline \multirow{4}{*}{$\begin{array}{l}1967 \\
\text { or earlier } \\
1968-69\end{array}$} & 125 & 22 & 22 & 38 & 39 & & 246 \\
\hline & $50 \cdot 8$ & 8.9 & 8.9 & $15 \cdot 4$ & 15.9 & & $12 \cdot 7$ \\
\hline & 31 & 7 & 5 & 11 & 13 & & 67 \\
\hline & $46 \cdot 3$ & $10 \cdot 4$ & $7 \cdot 5$ & $16 \cdot 4$ & $19 \cdot 4$ & & 3.5 \\
\hline \multirow[t]{2}{*}{$1970-71$} & 33 & 9 & 11 & 21 & 21 & & 95 \\
\hline & $34 \cdot 7$ & $9 \cdot 5$ & $11 \cdot 6$ & $22 \cdot 1$ & $22 \cdot 1$ & & 4.9 \\
\hline \multirow[t]{2}{*}{$1972-73$} & 60 & 18 & 20 & 52 & 42 & & 192 \\
\hline & $31 \cdot 3$ & 9.4 & $10 \cdot 4$ & $27 \cdot 1$ & 21.9 & & 9.9 \\
\hline \multirow[t]{2}{*}{$1974-75$} & 67 & 22 & 36 & 59 & 70 & & 254 \\
\hline & $26 \cdot 4$ & 8.7 & $14 \cdot 2$ & $23 \cdot 2$ & $27 \cdot 6$ & & $13 \cdot 1$ \\
\hline \multirow[t]{2}{*}{$1976-77$} & 80 & 19 & 44 & 72 & 101 & & 316 \\
\hline & $25 \cdot 3$ & $6 \cdot 0$ & 13.9 & $22 \cdot 8$ & $32 \cdot 0$ & & $16 \cdot 4$ \\
\hline \multirow[t]{2}{*}{$1978-79$} & 44 & 18 & 43 & 78 & 102 & & 285 \\
\hline & $15 \cdot 4$ & $6 \cdot 3$ & $15 \cdot 1$ & $27 \cdot 4$ & $35 \cdot 8$ & & $14 \cdot 8$ \\
\hline \multirow[t]{2}{*}{$1980-81$} & 37 & 8 & 30 & 73 & 93 & & 241 \\
\hline & 15.4 & $3 \cdot 3$ & $12 \cdot 4$ & $30 \cdot 3$ & $38 \cdot 6$ & & $12 \cdot 5$ \\
\hline \multirow[t]{3}{*}{ Not known } & & & & & & 236 & 236 \\
\hline & 477 & 123 & 211 & 404 & 481 & 236 & 1932 \\
\hline & $24 \cdot 7$ & $6 \cdot 4$ & 10.9 & 20.9 & $24 \cdot 9$ & $12 \cdot 2$ & $100 \cdot 0$ \\
\hline
\end{tabular}


generally lower for those born in later years, so that cumulative figures for those born in 1978 and 1979 were among the lowest values, whereas those for earlier years, such as 1972 and 1973, were much higher.

These figures are consistent with the falling total numbers of diagnoses of childhood coeliac disease from 1974 onwards, although in the same period the number of diagnoses in adult life were little altered.

\section{Discussion}

Changes in the apparent frequency of coeliac disease could be caused by real alterations in disease frequency, changes in the use of diagnostic procedures, and in the interpretations placed upon the findings. Jejunal biopsy has been undertaken increasingly often since its general introduction 20 years ago, and it has become clear that gluten intolerance commonly presents in ways other than simple steatorrhoea. In addition, histological changes have been ascribed to other causes, such as cow's milk protein intolerance.

Our data which show a low proportion of Coeliac Society members with birth dates in the more distant past are explainable by a combination of factors. Elderly people might be less likely to have the disease diagnosed, particularly if symptoms antedated jejunal biopsy, and even if the disease had been diagnosed earlier they might never have joined the Coeliac Society, which was not founded until 1968, and the proportions of elderly people in the population are in general low anyway.

Apparent later decreases in disease frequency are harder to explain. Our survey suggests that

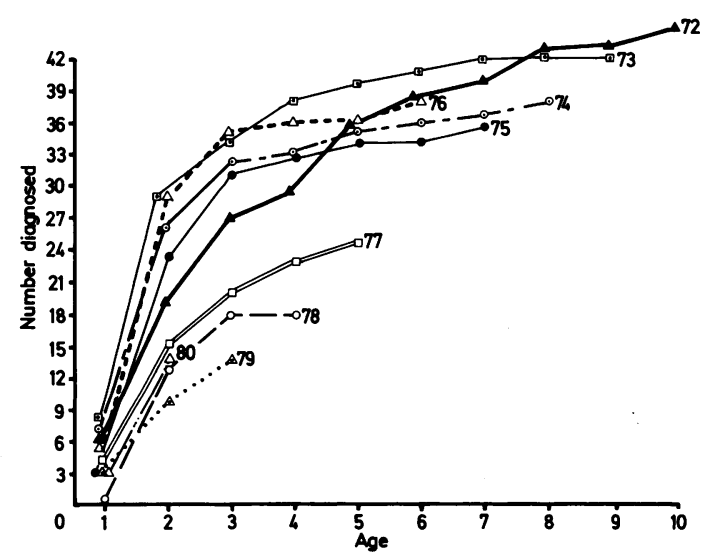

Fig. 2 Cumulative frequency distribution for Coeliac Society members born between 1972 and 1980 according to dates of disease diagnosis. individuals born in a 20 year period from 1941 to 1962 and also those born in the last few years are under-represented in Coeliac Society records. There is no particular reason why those born in these specific periods should be less likely to be registered with the Society, though we cannot exclude the possibility. The deficiency of births in the 20 years after 1940 might be explained if the disease tended to remit symptomatically after early childhood. Clinically it is well known that children firmly diagnosed as being coeliac may later lose their symptoms even though biopsy appearances remain abnormal. Those born in the two decades from 1940 are a group whose childhood took place before jejunal biopsy became available, and in whom clinical remission might then have taken place. Therefore, even if the diagnoses had been suspected on clinical grounds, they would be unlikely to be registered at the later date with the Coeliac Society if their disease had remitted clinically.

If this explanation was correct, then the numbers of coeliacs presenting and being diagnosed in late childhood would be expected to be maintained in the period up to 1962, whereas if general environmental factors predisposing to coeliac disease had become less prevalent then diagnoses would have been expected to become less common in all birth groups. Cohort analyses in fact showed that diagnostic rates in late childhood showed no specific decline over the period in question.

A reduced proportion of coeliacs in younger children in recent years is the reverse of what would be expected in a period when biopsy has become freely available. Possible reasons might be that coeliac disease diagnosis in infancy is not swiftly followed by Coeliac Society membership, and/or that criteria for diagnosis of coeliac disease have become much more strict lately. Neither explanation is convincing; the shape of the cumulative frequency cohort curves for births in 1977 and thereafter suggest a progressive fall in general level together with a flattening of the curves three to four years after birth. It seems very unlikely that delayed registration or diagnosis could account for such patterns, for if they occurred then the curves would not tend to flatten but would continue to rise slowly. Furthermore, scrutiny of recent membership records suggests that the vast majority of members of the Coeliac Society join within a year of disease diagnosis. Finally, it seems unlikely that half the diagnoses of coeliac disease which would have been made in, say 1974 were being rejected by 1978 and another group of diagnoses was being favoured.

Our observations accord with suggestions already made that coeliac disease is a diminishing clinical 
problem in infancy. One possibility is that reducing the gluten load in infant foods has delayed the diagnosis of coeliac disease, but it seems at least as likely that the true frequency of the disease is falling.

We are grateful for the cooperation of the executive committee of the Coeliac Society and its honorary secretary, Miss Kay Leighton; and for the financial support of the Research Committee of the Mersey Regional Health Authority.

\section{References}

1 Arthur LJH, Langman MJS. Prevalence of coeliac disease in Derby. In: McConnell RB, ed. The genetics of coeliac disease. Lancaster: MTP, 1981: 15-17.
2 Logan RFA, Rifkind EA, Ferguson A. The changing clinical picture of coeliac disease in Lothian, Scotland. In: McConnell RB, ed. The genetics of coeliac disease. Lancaster: MTP, 1981: 29-40.

3 Challacombe DN, Bayliss JM. Childhood coeliac disease is disappearing. Lancet 1980; 1: 1360.

4 Dossetor FJB, Gibson AMM, McNeish AS. Is the incidence of coeliac disease changing? Arch Dis Child 1979; 54: 977.

5 Dossetor FJB, Gibson AMM, McNeish AS. Childhood coeliac disease is disappearing. Lancet 1981; 1: 322-3.

6 Littlewood JM, Crollick AJ, Richards IDG. Childhood coeliac disease is disappearing. Lancet 1980; 2: 1359.

7 Stevens FM, Egan Mitchell B, McCarthy CF, McNicholl B. Factors in the epidemiology of coeliac disease in the West of Ireland. In: McConnell RB, ed. The genetics of coeliac disease. Lancaster: MTP, 1981: 7-14.

8 Draper NR, Smith H. Applied regression analysis. New York: Wiley, 1966 